\title{
Postdural puncture headache and pregabalin
}

This article was published in the following Dove Press journal:

Journal of Pain Research

25 February 2010

Number of times this article has been viewed

\section{Beyazit Zencirci}

Department of Anesthesiology and Reanimation, Mostas Private Health Hospital, Kahramanmaras, Turkey
Correspondence: Beyazit Zencirci Department of Anesthesiology and Reanimation, Mostas Private Health Hospital, Kahramanmaras, Turkey Email bzencirci@fastmail.fm
Background: Even if carried out under optimal conditions, postdural puncture headache is still a frustrating and unpleasant complication in spinal anesthesia. This syndrome has an estimated incidence from less than $1 \%$ to about $5 \%$ of patients undergoing spinal anesthesia, even in the highest risk subset, the young, female, and pregnant population.

Case presentation: In our two female cases, headaches started following spinal anesthesia on the 11th and 14th hours, respectively. No response was obtained from patients diagnosed with postdural puncture headache with classical treatments such as bed rest, hydration, oral analgesic, and caffeine combination as well as intravenous theophylline application. The treatment of oral pregablin, commonly used for cases that rejected epidural blood patch, caused a significant decrease in headache severity. Later, the two cases whose headaches were completely resolved were discharged from the hospital on the post-operative 7th day.

Conclusion: Postdural puncture headache is one of the most common complications of spinal anesthesia. Cerebral spinal fluid leakage into the epidural space has been proposed as the main mechanism responsible for this syndrome. Multiple methods of treatment have been applied with wide-ranging results. We detected that oral pregabalin application caused a significant decrease in the difficult and severe postdural puncture headaches of both our cases who did not respond to conventional treatments.

Keywords: postdural puncture headache, spinal anesthesia, pregabalin

\section{Introduction}

The first spinal anesthesia was carried out by Dr August Bier in 1899 and his anesthetic technique has become the standard practice for lower extremity and abdominal surgery worldwide. However, interestingly enough, the syndrome of postdural puncture headache (PDPH) was first described by Dr Bier in $1899 .{ }^{1}$

PDPH is still the most common postoperative complication of spinal anesthesia. The following factors are thought to influence the incidence of PDPH: age, sex, needle size, multiple dural punctures, and previous history of PDPH. ${ }^{2}$ Despite the fact that various mechanisms have been proposed for the cause of PDPH, the real etiology is not fully understood.

PDPH typically begins within two days (following spinal anesthesia procedure) but may be delayed for as long as two weeks and resolves spontaneously within a few days. Overhydration, peroral caffeine and theophylline, corticotropin, sumatriptan, epidural saline injection, and epidural blood patch (EBP) are the most common treatments.,

We have had positive results with oral pregabalin application in our two cases with resistant PDPHs that had not responded to the applied conventional classical treatments. 


\section{Case presentation}

Case 1, a 38-year-old woman, weighing $83 \mathrm{~kg}$ and $162 \mathrm{~cm}$ tall (body mass index [BMI]: $31.6 \mathrm{~kg} / \mathrm{m}^{2}$ ), was scheduled for vaginal hysterectomy operation. She had not been operated on previously. Case 2, a 21-year-old woman, weighing $62 \mathrm{~kg}$ and $151 \mathrm{~cm}$ tall (BMI: $27.2 \mathrm{~kg} / \mathrm{m}^{2}$ ), was scheduled for an inguinal hernia operation. The case had an appendectomy nine years ago under general anesthesia. Written informed consent was obtained from the patients for the publication of this case report and accompanying images.

The two cases did not have any systemic diseases and their pre-operative neurologic examination findings as well as biochemical and hematologic laboratory values were normal. Both patients were hydrated with at least $0.5 \mathrm{~L}$ of intravenous (iv) crystalloid solution before the procedure. Standard monitoring was used including noninvasive arterial blood pressure (NIBP), heart rate (HR), and pulse oximetry $\left(\mathrm{SPO}_{2}\right)$. Dural puncture was performed at the L3-4 interspace, in the sitting position, using a midline approach with 25-gauge Quincke spinal needles (Becton Dickinson, Franklin Lakes, NJ, USA). The bevel of the needle was kept parallel to the dural fibers. After observing the flow of cerebrospinal fluid (CSF) through the needle, $3 \mathrm{~mL}$ of $0.5 \%$ hyperbaric bupivacaine was injected. In both of two patients, spinal anesthesia was induced with a single puncture.

Surgical procedures were successfully carried out along with spinal anesthesia on our two cases whose spinal block levels had increased to Th 10-11 dermatome level. Headaches of the cases, whose motor and sensory blocks were completely over, started respectively on the 11th and 14th hours following the spinal anesthesia procedure. According to the anamnesis (severe visual analog scale [VAS]: $8-9 \mathrm{~cm}$, dull permanent and nonthrobbing pain in fronto-occipital location) and examination findings (moderate to severe headache when sitting or ambulating and no neck stiffness) of the two cases, it was decided that they had PDPH.

Both cases were started a combined oral medication containing paracetamol and caffeine $(300 \mathrm{mg} /$ day) with bed rest and hydration (not agresssive). Twenty-four hours after the beginning of treatment, there was no alleviation of the pains and as nausea also started, theophylline application was started. Two cases were given $200 \mathrm{mg}$ intravenous theophyl-

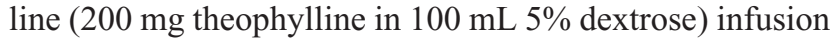
over 40 minutes so cases who didn't report any decrease of VAS pretreatment values, four hours after the theophylline infusion were given a second theophylline infusion under the same conditions. Headaches did not respond to this treatment, although neurologic examination of the cases was normal and meningeal irritation findings were negative; therefore cranial tomographies of both cases were taken but no pathological conditions were detected.

Thirty-six hours after the beginning of the headaches, EBP was offered to the patients. However, both patients mentioned that they had been having headaches due to spinal anesthesia and that they would not accept another injection on the same area even for treatment. Therefore, we did not have a chance to use EBP for our cases.

Thereupon, we decided to use pregabalin containing an analogue gamma-aminobutyric acid such as gabapentin ${ }^{5,6}$ that has been shown to have positive effects on PDPH. Oral pregabalin treatment of $150 \mathrm{mg} /$ day $(50 \mathrm{mg}$ at eight-hour intervals) was started. Following the first dose, on the 2nd and 3rd hours, respectively, there was a decrease in the headache VAS scores of the cases. After the 12th hour, VAS values were below 3 . During the subsequent three-day pregabalin treatment, the cases did not complain of headache. Thereupon, one daily medication dose was skipped and it was stopped after two days. The patients did not complain of headache. No side effects except sedation were observed during treatment and, we believe, the cases who had been suffering from headaches for two days were in need of sedation. Both cases were discharged from the hospital on the post-operative 7 th day without any problem. The patients were called for an examination after one month and no pathological findings were observed.

\section{Discussion}

More than 100 years have passed since the initial description of the PDPH and it still continues to occur. ${ }^{1}$ The International Classification of Headache Disorders, 2nd edition describes PDPH under paragraph 7.2.1. ${ }^{7}$

PDPH is postulated to be a consequence of one of two nonmutually exclusive mechanisms, both involving CSF leaking through a needle-induced dural hole. One hypothesis is that this decrease in CSF results in an increase blood volume from vasodilation secondary to the Monro-Kellie doctrine because the sum of the volumes of the brain matter, CSF, and blood must remain the same. The second hypothesis is that the decrease in CSF volume results in sagging of the brain in the cranial vault when the patient assumes the upright position, which pulls on the falx cerebri, cerebral blood vessels, and tentorium, resulting in excruciating positional head pain. This headache may be accompanied by occiput, neck and shoulder pain, upper limb pains or paresthesias, nausea and vomiting, photophobia or cranial nerve palsies including but not limited to diplopia, visual blurring, and hearing loss. cerebrospinal fluid. ${ }^{8}$ 
Risk factors for PDPH include young age, lesser body mass index, female gender, pregnancy and labor, history of recurrent headaches or previous PDPH, size of the needle, direction of the cutting needle bevel when puncturing the dura, and other technical factors in the performance of lumbar puncture. ${ }^{910}$ Although relatively thin spinal needles (25-gauge Quincke spinal needle) were used, the procedure was completed at once and needle direction was parallel to the dura, we came across with PDPH in our cases and we believe this was due to the fact that in both cases were relatively young (aged below 40 years) and female.

The classic PDPH is described as a severe, dull, nonthrobbing pain usually fronto-occipital in location. It is now recognized that the patient may also suffer from associated nausea, vomiting, visual disturbances, tinnitus or deafness. ${ }^{2} \mathrm{PDPH}$ can be severe and is usually aggravated by sitting, standing, and walking because of the descending shift of the brain, which stretches pain-sensitive meningeal structures. ${ }^{11,12}$

Therapy for PDPH begins with proper diagnosis. Misdiagnosis is a strong possibility. In particular, the physician should be careful to rule out treatable catastrophic medical problems such as meningitis and subarachnoid bleeding. Once the diagnosis is made, most authors recommend 24 hours of conservative therapy, since the natural history is one of spontaneous resolution. ${ }^{2}$ Bed rest is effective in that it avoids the upright position, which aggravates PDPH. Analgesics given orally, including mild opiates, also routinely bring some relief during the observational period. Aggressive hydration and tight abdominal binders are no longer recommended.

If the headache persists and is disabling to the patient, or if nausea, vomiting, visual disturbance or tinnitus occurs, the diagnosis should be reconsidered. Once other important causes of severe headache are again ruled out, the therapeutic options include caffeine given intravenously, an EBP and epidural administration of saline. ${ }^{2}$

Pharmacological management of PDPH is a minimally invasive treatment modality. Severe headaches such as PDPH commonly present with nausea and this limits the effect of peroral medications. It would be useful to use parenteral medications for rapid and effective treatment and a noninvasive procedure is preferable. However, invasive treatments (like EBP etc.) for PDPH have known complications, such as infection and exacerbation of pain. ${ }^{13}$ When EBP is used in patients suffering from moderate to severe or prolonged PDPH, two mechanisms likely bring about this effect: formation of a plug in the dural defect, which stops the loss of CSF, and simultaneous reduction in the volume of the subarachnoid space through expansion of the epidural space, which eliminates the relative CSF deficiency. ${ }^{14}$

Pregabalin, like gabapentin, is an antiepileptic drug and a structural analogue of gamma-aminobutyric acid (GABA). Pregabalin does not undergo hepatic metabolism and is not bound to plasma proteins. It is renally excreted, and $98 \%$ of the absorbed dose is excreted unchanged in the urine. Absorption of pregabalin is not saturable (contrary to gabapentin), resulting in a linear pharmacokinetic profile. It is rapidly absorbed with peak blood concentrations within one hour. Average bioavailability exceeds $90 \%$ (higher than gabapentin) and is independent of dose, which may produce a more predictable patient response. The elimination half-life of pregabalin ranges from 5.5 to 6.7 hours, and is independent of dose (contrary to gabapentin) and repeated dose administration. ${ }^{15}$ Pregabalin binds to the alpha-2-delta subunit of the N-type calcium channels, and modulates calcium influx at nerve terminals, and, thereby, reduces the release of several neurotransmitters, including glutamate, noradrenaline, serotonin, dopamine, and substance $\mathrm{P} .{ }^{16}$

Cabrera Schulmeyer and colleagues ${ }^{17}$ determined that a single dose of pregabalin reduced postoperative morphine consumption after a sleeve gastrectomy during the first 24 hours after surgery. Freedman and colleauges ${ }^{18}$ found out that perioperative pregabalin administration in patients undergoing augmentation mammaplasty reduced postoperative narcotic use by $70 \%$. Agarwal and colleagues' study results showed that a single preoperative oral dose of pregabalin is an effective method for reducing postoperative pain and fentanyl consumption in patients undergoing laparoscopic cholecystectomy. ${ }^{19}$

On the other hand, pregabalin, like gabapentin, was shown to be effective in several animal models of neuropathic pain, incisional injury, inflammatory injury, and formalininduced injury. ${ }^{15}$ However, studies have demonstrated that a clinically efficacious dose of chronic oral pregabalin inhibits measures of central sensitization in the electrical hyperalgesia model in human volunteers. ${ }^{20}$ Thus pregabalin, which has been effective in reducing hyperalgesia in pain model, may play an important role in acute postoperative pain in humans.

Eventually, maybe the exact mechanism of action of pregabalin is not well understood but clinical experience and our observations have demonstrated its analgesic efficacy and safety in PDPH. Our findings (via two patients) demonstrated that $150 \mathrm{mg} /$ day of oral pregabalin significantly decreases PDPH. 


\section{Conclusion}

PDPH continues to be a major problem for spinal anesthesia. Different treatment modalities have been implemented on patients with PPDH, including bed rest, hydration or overhydration, peroral caffeine or theophylline, corticosteroids, sumatriptan, abdominal binder, EBP, epidural saline infusion, etc. In the light of the positive results we received from the two cases, we believe oral pregabalin application could be an alternative for stubborn PDPH cases that do not respond to classical treatments and that further studies are required on this subject.

\section{Disclosure}

The author declares that he has no competing interests in this work.

\section{References}

1. Smith HM, Bacon DR. The history of anesthesia. In: Barash PG, Cullen BF, Stoelting RK. Clinical Anesthesia, 5th edition. Philadelphia, PA: Lippincott; 2006:10.

2. Reid JA, Thorburn J. Headache after spinal anesthesia. Br J Anaesth. 1991;67:674-677.

3. Frank RL. Lumbar puncture and post-dural puncture headaches: implications for the emergency physician. J Emerg Med. 2008;35: 149-157.

4. Reamy BV. Post-epidural headache: how late can it occur? J Am Board Fam Med. 2009;22:202-205.

5. Erol DD. The effect of oral gabapentin on postdural puncture headache. Acute Pain. 2006;8:169-173.

6. Lin YT, Sheen MJ, Huang ST, Horng HC, Cherng CH, Wong CS, Hot ST. Gabapentin relieves post-dural puncture headache-a report of two cases. Acta Anaesthesiol Taiwan. 2007;45:47-51.
7. Headache Classification Subcommittee of the International Headache Society. The International Classification of Headache Disorders. 2nd edition. Cephalalgia. 2004;24(suppl 1):1-160.

8. Arendt K, Demaerschalk BM, Wingerchuk DM, Camann W. Atraumatic lumbar puncture needles: after all these years, are we still missing the point? Neurologist. 2009;15:17-20.

9. Lybecker H, Møller JT, May O, et al. Incidence and prediction of postdural puncture headache. A prospective study of 1021 spinal anesthesias. Anesth Analg. 1990;70:389-394.

10. Richman JM, Joe EM, Cohen SR, et al. Bevel direction and postdural puncture headache: a meta-analysis. Neurologist. 2006;12:224-228.

11. Weeks SK. Postpartum headache. In: Chesnut DH, editor. Obstetric Anesthesia: Principles and Practice, 3rd ed. Philadelphia, PA: Mosby; 2004:564-574.

12. Harrington BE. Postdural puncture headache and the development of the epidural blood patch. Reg Anesth Pain Med. 2004;29:136-163.

13. Choi A, Laurito CE, Cunnigham FE. Pharmacologic management of postdural puncture headache. Ann Pharmacother. 1996;30:831-839.

14. Morewood GH. A rational approach to the cause, prevention and treatment of postdural puncture headache. CMAJ. 1993;149:1087-1093.

15. Gajraj NM. Pregabalin: its pharmacology and use in pain management. Anesth Analg. 2007;105:1805-1815.

16. Fink K, Dooley DJ, Meder WP, et al. Inhibition of neuronal $\mathrm{Ca}(2+)$ influx by gabapentin and pregabalin in the human neocortex. Neuropharmacology. 2002;42:229-236.

17. Cabrera Schulmeyer MC, de la Maza J, Ovalle C, Farias C, Vives I. Analgesic effects of a single preoperative dose of pregabalin after laparoscopic sleeve gastrectomy. Obes Surg. 2009; Aug 29 [Epub ahead of print].

18. Freedman BM, O'Hara E. Pregabalin has opioid-sparing effects following augmentation mammaplasty. Aesthet Surg J. 2008;28:421-424.

19. Agarwal A, Gautam S, Gupta D, Agarwal S, Singh PK, Singh U. Evaluation of a single preoperative dose of pregabalin for attenuation of postoperative pain after laparoscopic cholecystectomy. Br J Anaesth. 2008;101:700-704.

20. Chizh BA, Göhring M, Tröster A, Quartey GK, Schmelz M, Koppert W. Effects of oral pregabalin and aprepitant on pain and central sensitization in the electrical hyperalgesia model in human volunteers. Br J Anaesth. 2007;98:246-254.
Journal of Pain Research

\section{Publish your work in this journal}

The Journal of Pain Research is an international, peer-reviewed, open access, online journal that welcomes laboratory and clinical findings in the fields of pain research and the prevention and management of pain. Original research, reviews, symposium reports, hypothesis formation and commentaries are all considered for publication.
The manuscript management system is completely online and includes a very quick and fair peer-review system, which is all easy to use. Visit http://www.dovepress.com/testimonials.php to read real quotes from published authors. 